Portland State University

PDXScholar

\title{
A Comparative Study of Perceptual Ratings and Fundamental Frequency in Female and Male Esophageal Voices
}

Anne Terese Heinrich

Portland State University

Follow this and additional works at: https://pdxscholar.library.pdx.edu/open_access_etds

Part of the Gender, Race, Sexuality, and Ethnicity in Communication Commons, and the Speech Pathology and Audiology Commons

Let us know how access to this document benefits you.

\section{Recommended Citation}

Heinrich, Anne Terese, "A Comparative Study of Perceptual Ratings and Fundamental Frequency in Female and Male Esophageal Voices" (1978). Dissertations and Theses. Paper 2848.

https://doi.org/10.15760/etd.2842

This Thesis is brought to you for free and open access. It has been accepted for inclusion in Dissertations and Theses by an authorized administrator of PDXScholar. Please contact us if we can make this document more accessible: pdxscholar@pdx.edu. 
AN ABSTRACT OF THE THESIS OF Anne Terese Heinrich for the Master of Science in Speech Communication: Emphasis 1n Speech Pathology/Audiology presented May 26, 1978.

Title: A Comparative Study of Perceptual Ratings and Fundamental Frequency in Female and Male Esophageal Voices.

APPROVED BY MEMBERS OF THE THESIS COMMITTEE:

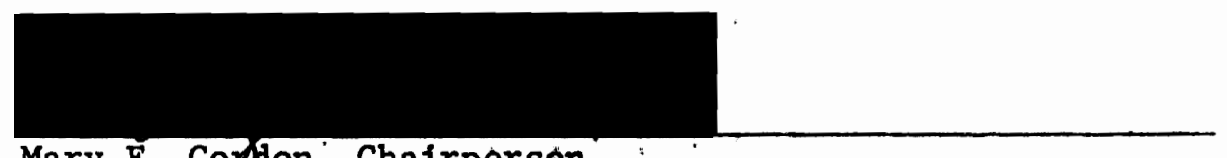
Mary E. Goption; Chairperson

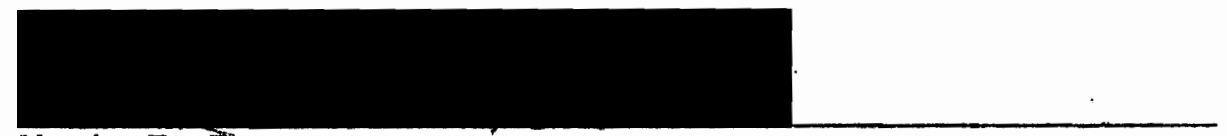
Marie T. Rau

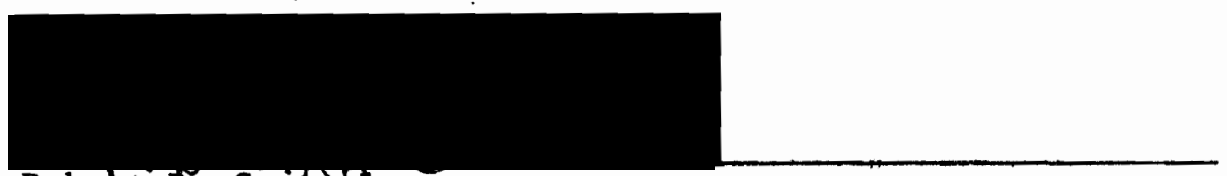

Robeft L. Casted

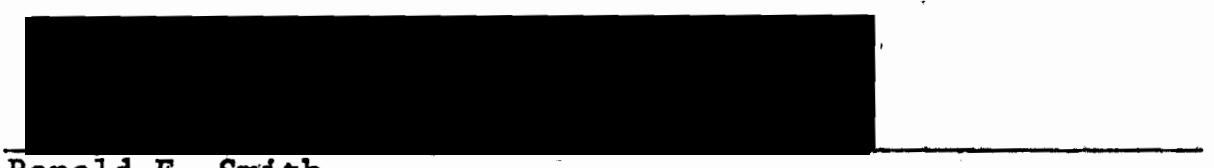

Removal of the larynx necessitates an altered means of speaking. Esophageal voice is the traditional and generally recommended substitute voice. Because the pitch of the female esophageal voice may be strikingly lower than that for normally speaking women, fundamental frequency may be a variable influencing whether female esophageal voice is considered socially acceptable. More importantly, listeners máy apply different 
standards to male and female esophageal voices, thus necessitating an approach in research that treats them as separate samples.

This study proposed to determine if male and female esophageal voices were rated in the same manner by naive listeners. Answers to the following questions were sought:

1. Is there a difference in the social acceptability ratings given to female esophageal voices compared to male esophageal voices, when the speakers are matched for speaking ability?

2. Does a relationship exist between the fundamental frequencies of female esophageal volces and ratings of social acceptability given by naive listeners?

3. Does a relationship exist between the fundamental frequencies of male esophageal volces and ratings of social acceptability given by nalve listeners?

4. Do male and female nalve listeners rate female esophageal voices similarly?

The subjects for this study were eight female and eight male esophageal speakers, matched for speech competency by the Barton-Hejna Scale for Esophagea1 Speech Competency.

The subjects were tape recorded reading the first paragraph of the "Rainbow Passage" and saying a series of four CVC syllables with the vowel portions prolonged. The second sentence of the passage and the four syllables were extracted and placed on a second generation tape. Listeners rated each esophageal voice sample for volce social acceptability (VSA). Additionally, the vowel portions of the four monosyllabic words were subjected to sonographic analysis; these were averaged and the average considered to be the "fundamental frequency."

Analysis of the ratings given to the male and female volices indicated that knowing the speaker's sex was not related to the soclal acceptability of the esophageal voice. The total mean VSA rating for the 
male voices was not significantly different from the total mean VSA rating given to the female voices. These findings, however, do not indicate identical standards of soctal acceptability are applied to each voice.

Analysis of fundamental frequencies and VSA ratings for female voices shows a moderate correlation. The fundamental frequency, then, may be considered a factor related to the VSA rating given to a female esophageal voice. A negligible relationship was found when correlating the fundamental frequencles of male esophageal voices and VSA ratings. The necessity of treating male and female esophageal voices as separate samples in perceptual research is supported.

The findings indicate the sex of the listeners did not influence the rating scores assigned to the voices. Male and female listeners rated the esophageal volces in a simflar manner. 
A COMPARATIVE STUDY OF PERCEPTUAL RATINGS AND FUNDAMENTAL FREQUENCY IN FEMALE AND MALE ESOPHAGEAL VOICES

\author{
by
}

ANNE TERESE HEINRICH

A thesis submitted in partial fulfillment of the requirements for the degree of

MASTER OF SCIENCE

in

SPEECH COMMUNICATION

EMPHASIS SPEECH PATHOLOGY/AUDIOLOGY

Portland State University

1978 
TO THE OFFICE OF GRADUATE STUDIES AND RESEARCH:

The members of the Committee approve the thesis of Anne Terese Heinrich presented May 26, 1978.

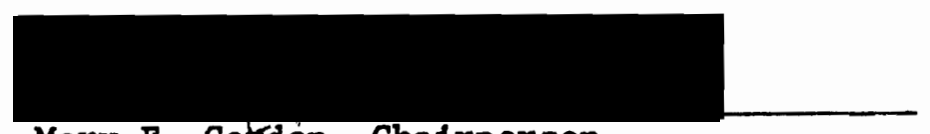

Mary E. Gofdon, Chatrperson

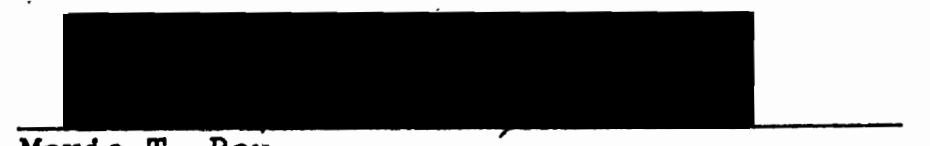

Marte T. Rau

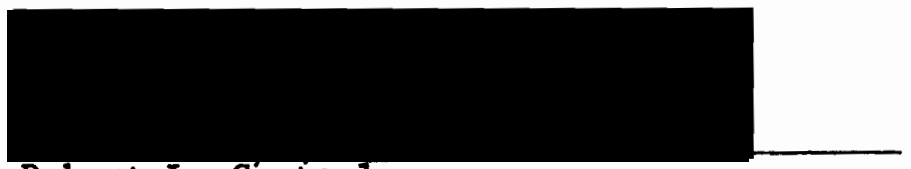

Robert I. Casteel

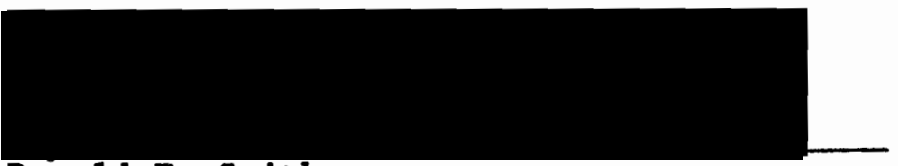

Ronald E. Smith

APPROVED :

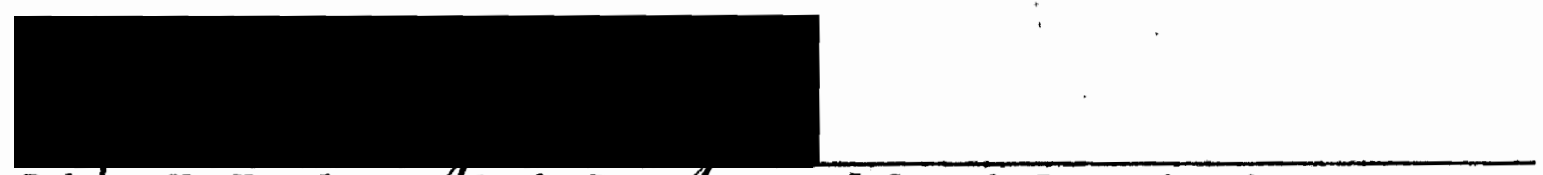

Robdrt W. Vogelsang/Head, Depayfment of Speech Communication

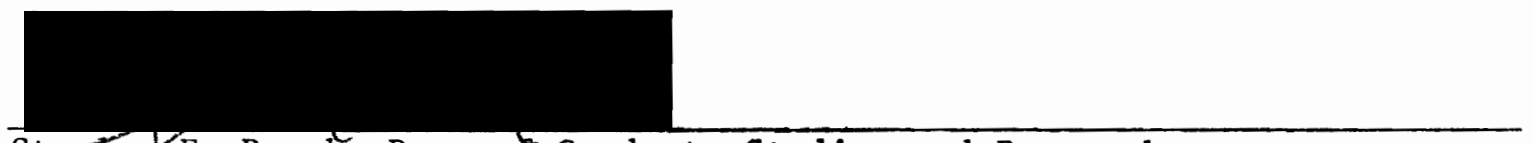

Stanley E. Rauch, Dean of Graduate Studies and Research 


\section{ACKNOWLEDGEMENTS}

If asked four months ago about this study, I would have replied in very audible tones that it was the product of countless worried and frustrated hours, fear of an insurmountable task, continual griping, and that it elicited some of the most creative avoidance behaviors known.

Through the months-long process, however, my skills as a researcher and writer were discovered and refined. Under the guidance of Mary Gordon, the undertaking was divided into manageable tasks. My initial shirking was followed by positive actions. Despite the negative aspects to which I alluded, I enjoyed the experience and consider my thesis with pride.

The positive actions of many people provided the basis upon which the success of the study is built. I would like to acknowledge their valuable contributions:

My friends who use esophageal voice, especially Betty Record, Edna Rama and M. H. Hollyfield;

Mary Gordon, chairperson and guide into heretofore unexplored realms;

Judy Rau and Dr. Ronald Smith, for their constructive comments and participation on the thesis committee;

Dr. Robert English, sonograph instruction; Dr. James Maurer, rating esophageal voices; Debby Kallen, transportation; Sally Hancock, precious 
time; Deon Shope, naive listeners; Mr. and Mrs. A. G. Heinrich, support (of all kinds).

Special feeling is accorded to Barbara Mathers and Dr. Robert

Casteel, not only for their helpful participation on this thesis, but for making the pursult of an M.S. degree most satisfying and meaningful. 
TABLE OF CONTENTS

PAGE

ACKNOWLEDGEMENTS

LIST OF TABLES

LIST OF FIGURES

CHAPTER

I INTRODUCTION

Statement of Purpose

II REVIEW OF THE LITERATURE

Removal of the Larynx

The Mechanism of Esophageal Voice . . . . . 6

Characteristics of Esophagea1 Voite . . . . . 7

Female Esophageal Voice . . . . . . . . . 8

Relationship Between Acoustic Parameters

and Perceptual Judgements of Esophageal

METHODS AND PROCEDURES . . . . . . . . . . . . . 13

Methods . . . . . . . . . . . . . . 13

General Plan of Study

Subjects

Listeners

Instrumentation

Procedures

Recording Procedures

Rating Procedures 
CHAPTER

Measurement and Analysis of Data . . . . .

Acoustic Measurement

Statistical Analysis

IV RESULTS AND DISCUSSION

Results . . . . . . . . . . . . . . 18

Discussion . . . . . . . . . . . . . . 22

$\mathrm{V}$ SUMMARY AND IMPLICATIONS . . . . . . . . . . . 32

Summary . . • • . . . . . . . . . . 32

Implications . . . . . . . . . . . . 34

Clinical

Research

BIBLIOGRAPHY

APPENDIX 


\section{LIST OF TABLES}

TABLE

PAGE

I Rating Scale Intrajudge Reliability . . . . . .

II Rating Scale Interjudge Reliability . . . . . . . .

III Sample Mean Fundamental Frequency . . . . . . . .

IV Mean Fundamental Frequency and Mean Voice Social Acceptability Ratings . . . . . . . . . .

V Barton-Hejna Ratings, Mean Voice Social Acceptability Ratings, and Fundamental Frequency For Matched Pairs . . . . . . . . . . . . .

VI InvestIgations of Esophageal Volce Fundamental Frequencles . . . . . . . . . . . . . . 


\section{LIST OF FIGURES}

FIGURE

PAGE

1 The Head and Neck Before and After Total

Laryngectomy 


\section{CHAPTER I}

\section{INTRODUCTION AND PURPOSE}

Much of the research on esophageal voice has been directed toward obtaining data from samples of male esophageal speakers. Male subjects have been used in studies to obtain statistical and descriptive data on the physiological correlates of esophageal speech (DiCarlo, Amster and Herer, 1955; Snidecor and Isshiki, 1965a; Lavorato, 1970; Murray and Brown, 1975), the acoustic parameters of fundamental frequency, intensity and rate (Snidecor and Curry, 1959), and dimensions of articulatory change (Christensen and Weinberg, 1976; Nichols, 1976).

Attempts to relate varlous parameters of the esopkageal speaker's performance with listener judgements of speech intelligibility, communicative effectiveness, or social acceptability have included comparisons of the esophageal speaker to normal speakers (Tikofsky, 1965; Gilmore, 1974) and to artificial larnyx users (Hyman, 1955; McCroskey and Mulligan, 1963; Shames, Font and Matthews, 1963; Bennett and Weinberg, 1973). Judgements have been made under varying environmental conditions (Berry and Knight, 1975; Horil and Weinberg, 1975), according to 1istener sophistication (Hoops and Nol1, 1971), and in relation to speaker variability in terms of frequency, duration, rate, intensity, phrasing, articulation and auditory functioning (Shipp, 1967; Hoops and No11, 1969; Hoops and Guzek, 1974; Martin, Hoops and Shanks, 1974; Filter and Hyman, 1975). With the exception of rate, these investigations have resulted in conflicting evidence as to the contribution of each variable 
to listeners' perceptual judgements. Rate is the common variable found to be significant by several investigators (Shipp, 1967; Hoops and Noll, 1969; Filter and Hyman, 1975). The studies mentioned were conducted with male populations (Hoops and Noll, 1969) or did not report separate results for the female subjects (Shipp, 1967; Filter and Hyman, 1975). It is possible fundamental frequency might be a more significant variable were female speakers considered.

The importance of treating male and female speakers as separate populations in perceptual studies of fundamental frequency becomes apparent in consideration of research by Weinberg and Bennett (1972a). A significant difference was found between the mean fundamental frequency of a sample of female esophageal speakers $(87 \mathrm{~Hz})$ and that produced by the male sample $(69 \mathrm{~Hz})$. It also was found that naive listeners can reliably and accurately identify the sex of esophageal speakers (Weinberg and Bennett, 19.75). Male esophageal speakers tend to average one octave below the socially accepted fundamental frequency standard for their sex. Females, though the esophageal voice may be at a higher fundamental frequency than male esophageal voices, may be approximately two octaves below the soctally accepted standard for females (Curry, Snidecor and Isshiki, 1973). Naive listeners may apply different standards in determining the social acceptability of the female esophageal voice than that of the male esophageal voice based on the relative degree of pitch difference compared to normal speakers.

\section{Statement of Purpose}

The purpose of the present study was to compare social acceptability ratings given by naive listeners to male and female esophageal 
voices. The following questions were asked:

1. Is there a difference in the social acceptability ratings given to female esophageal voices compared to male esophageal voices, when the speakers are matched for speaking ability?

2. Does a relationship exist between the fundamental frequencies of female esophageal voices and ratings of social acceptability given by naive listeners?

3. Does a relationship exist between the fundamental frequency of male esophageal voices and ratings of social acceptability given by naive listeners?

4. Do male and female naive listeners rate female esophageal voices similarly? 
CHAPTER II

REVIEW OF THE LITERATURE

To understand the acoustic and perceptual parameters of esophageal voice, it is necessary to know the physiological and anatomical conditions under which the pseudo-voice is produced. The laryngectomy operation, the mechanism and characteristics of esophageal voice, and "special" problems of the female laryngectomee are reviewed. Studies that relate the acoustic parameters (e.g., fundamental frequency) of esophageal voice to perceptual judgements (e.g., acceptability) conclude the chapter.

\section{Removal of the Larynx}

In a total laryngectomy operation, the oral cavity is isolated from the pulmonary tract by laryngeal excision. The best known procedure removes the entire larynx, including the cartilages and the intrinsic muscles. The attached extrinsic muscles that originate in the larynx and insert in the hyold bone are usually included. The hyold bone may or may not be removed. After removal of the larynx, the end of the trachea is brought to the surface of the skin at the lower level of the neck. A stoma (breathing hole) is created here; air passes directly into the lungs without passing through the upper respiratory channels of the nose, mouth and throat (Figure 1) (Pressman, 1962).

This type of anatomical and physiological alteration of the respiratory system necessitates the development of a new speaking method: 

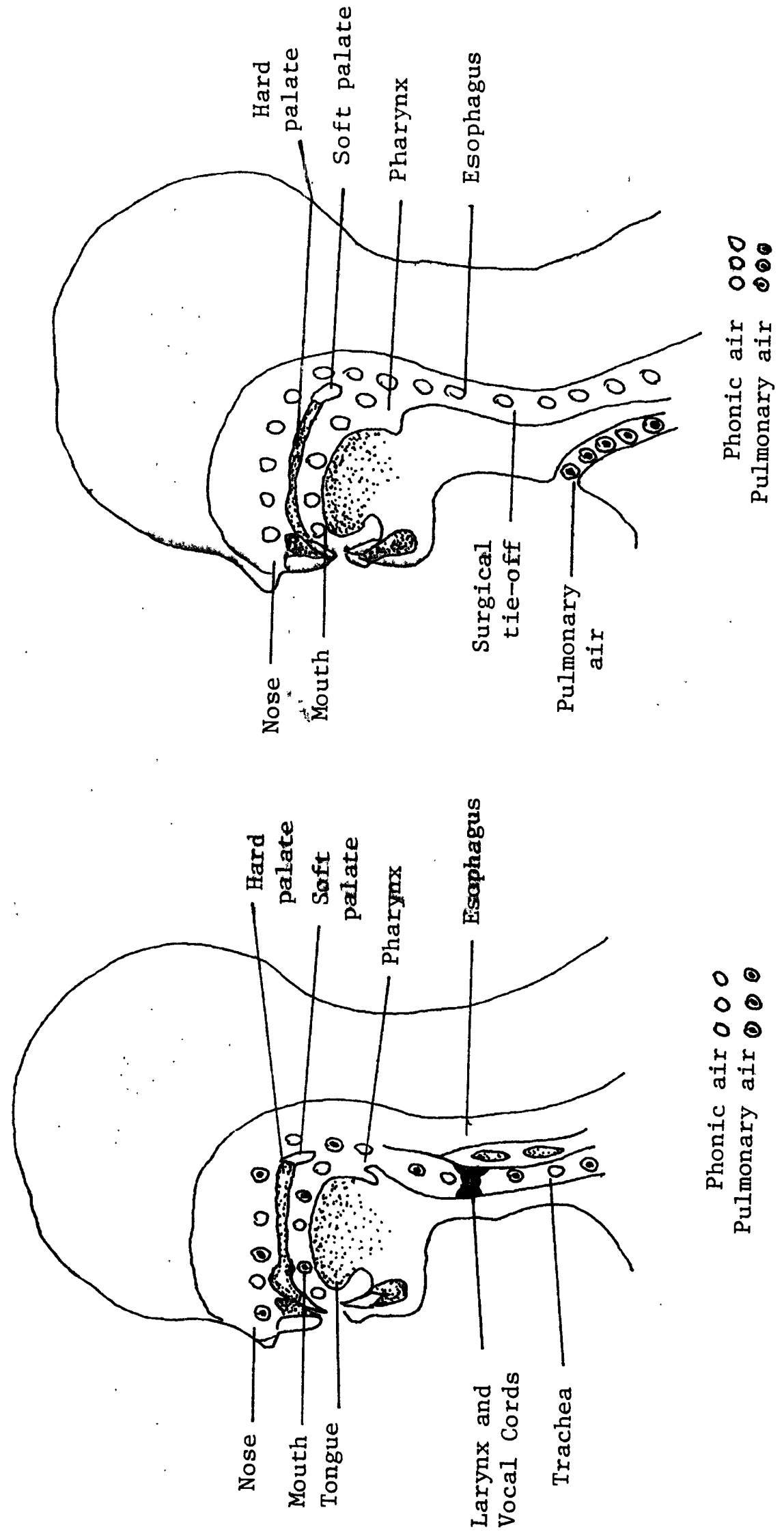

Oิ) 
esophageal speech or speech produced by an artificial larynx. In the case of a standard laryngectomy operation, esophageal voice is the traditional and generally recommended substitute voice. Though considered by some to be more desirable than the artificial 1arynx (Levin, 1952; Hunt, 1964; Shanks, 1967), statistica1 predictions for success are not very optimistic (Snidecor, 1975). JThe percentage of laryngectomees using intelligible esophageal speech ranges from as low as 43 percent (King, Lowlks, and Peirson, 1968) to 84 percent (Hunt, 1964).

\section{The Mechanism of Esophagea1 Voice}

The posterior wall of the larynx is the anterior wall of the esophagus. Removal of the larynx usually results in the surgical narrowing of a band of muscle tissue in the upper esophagus, most often located at

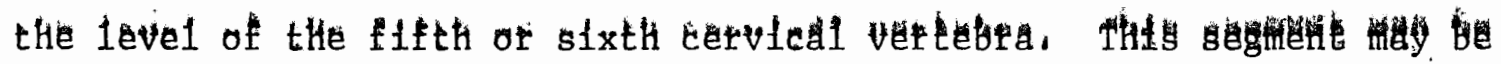
made up of muscle fibers from the superior esophageal sphincter, the cricopharyngeous and the inferior constrictor; it is often referred to as the pharyngo-esophageal (P-E) segment.

The laryngectomee compresses air from his mouth and hypopharynx immediately above the P-E segment using one or a combination of three methods: "Sniffing" the air through the nose or mouth; injecting air with a pumping-like motion of the tongue; compression of air in preparation for the production of either a plosive or a fricative sound. When the positive air pressure is greater above than the pressure below the segment (negative pressure exists in the esophagus in its natural state), the vacuum causes the positive air in the oral and pharyngeal cavities to be sucked in through the P-E segment. The stream of air sets the tissues into vibration. The sound is converted into speech by 
movements of the articulators, which remain unaltered after surgery (Salmon, 1971; Knox, 1978).

\section{Characteristics of Esophageal Voice}

The voice and speech productions resulting from air expelled from the upper alimentary tract through a pseudoglottis have been the foci of many investigations. In general, the effectiveness of esophageal speech is limited by inadequate air support, resulting in an increased number of pauses. The speaker's effective speaking rate will be reduced and speech may be either "choppy" or hesitant as he pauses to recharge the esophagus with air (Snidecor and Isshiki, 1965a).

Snidecor (1951) found normal speakers (phonating from 60 to 75 percent of the time during continuous'speech. For esophageal speakers, the range of phonated time was from 38 to 57 percent (Snidecor and Isșhiki, 1965b). Atcording to Sthadecor and Curry (1959), a speaking rate of 80 to 128 words per minute is realistic for esophageal speakers, compared to 166 words per minute for normal speakers.

An outstanding characteristic of the esophageal voice is its low pitch (Snidecor, 1975). The comparatively large mass of the vibrating pseudoglottis and low airflow rates cause the pitch of esophageal speech to be considerably lower than normal. The average normal male voice is perceived to be about $132 \mathrm{~Hz}$, while the mature female speaker is approximately $220 \mathrm{~Hz}$. The male esophageal speaker averages $63 \mathrm{~Hz}$ (Snidecor, 1975). The average fundamental frequency of 15 female esophageal voices was measured to be $87 \mathrm{~Hz}$ (Weinberg and Bennett, 1972a). Curry et al. (1973) indicated the female esophageal voice may be two octaves below the speaker's presurgical voice. 'Despite the low pitch, a normal range 
of pitch variability can be expected. The esophagea1 speaker may sound monotone despite his ability to alter pitch because the frequency of vibration is often less than $100 \mathrm{~Hz}$, and listeners are unable to perceive changes in such low pitched voices (Diedrich and Youngstrom, 1966). In addition, the intensity of the esophageal voice is reduced, but is sufficient to be heard in a group of 25 people under ideal listening conditions (Snidecor, 1971).

The "hoarse" quality of esophageal voice also differentiates it from the normal voice. The nature of the pseudoglottis and the reduced elasticity of the tissues due to scarring account for the irregular, aperiodic noise in the spectrum of esophageal voice. The vibration of accumulated mucus at the pseudoglottis also contributes to the complexity of the vibratory pattern (Nichols, 1962).

\section{Female Esophageal Voice}

The literature suggests female laryngectomees are less motivated to learn to speak esophageally for several reasons: the hoarse quality; the low, "unfamiliar" pitch; and fear of social rejection due to either pitch and quality differences or the way in which she produces sound. Gardner (1966) made the following observations based on a survey answered by 237 laryngectomized women:

Successful adjustment depends on the nature and temperament of the patient... The masculine esophageal voice attracts attention; it is not acceptable to the public... She is reluctant to use her masculine voice for fear of losing her position in relationship with the other sex.

Putney (1958) included 23 women in his study, two-thirds of whom did not learn esophageal speech. He speculated that "...psychologic elements associated with fixed emotional attitudes were strong factors in 
women and generally deterred them from perseverence." Gilchrist (1973) agreed that the low tones of esophageal speech were likely to be embarrassing and distasteful to women; thus, they experience a higher failure rate. The esophageal voice seems to be more unfamiliar and unpleasant for the female than the male.

Svane-Knudsen (1960) found laryngectomized women fear social rejection, due to listeners' misconception that the laryngectomee's hoarse and rough voice is the result of a life spoiled by "beer and tobacco." The laryngectomee may have been told the production of the esophageal voice is based on a physiological principle similar to belching. Though this is erroneous, the laryngectomee may feel she is being asked to talk in a voice that is culturally rejected (Klinger, 1971).

Cooper (1973) stated all speakers visualize themselves as being a certain type of speaker with a certain type of voice. This "vocal image" is a determinant in the successful acquisition of esophageal voice. A laryngectomized woman must deal with the sound of her presurgical voice compared to the extremely low pitched esophageal voice which is noticeable and varies from societal standards.

\section{Relationship Between Acoustic Parameters and Perceptual Judgements of Esophageal Voice}

Oral communication involves the interaction of the speaker and his listeners. Various studies have attempted to correlate physical measurements of the parameters of esophageal voice to listener.judgements of "social acceptability" or "speech effectiveness." Despite her special problems, few researchers have dealt with the female laryngectomee, either in physical measurement or perceptual studies of esophageal 
speech. Studies investigating the acoustic variables of esophageal speech related to acceptability ratings have used male populations or did not report separate results for female subjects.

A sample of 33 esophageal speakers was judged for acceptability on a five-point scale in an Investigation by Shipp (1967). These phonatory variables of esophageal speech were analyzed: mean, standard deviation and 90 percent range of fundamental frequency; total duration; and percentage of entire utterance spent in periodic phonation, aperiodic phonation, and silence. Factors coincident with above-average acceptability ratings included a higher mean fundamental frequency, a more rapid utterance of the test sentence, a greater proportion of periodic phonation, and a lesser proportion of both aperiodic phonation and silence. There was great variability among the esophageal speakers' average frequency leve1s, and the higher mean level was a "desirable" trait. Frequency variation appeared to be unimportant, but the location within the frequency spectrum where the variation occurred may have affected the listeners' evaluation of speech acceptability. Shipp did not report what percentage, if any, of the subjects were female. It is difficult to interpret the importance of fundamental frequency as a variable in Shipp's study, because the sex of the speakers was not indicated.

Filter (1971) showed that 10 female esophageal speakers received significantly higher effectiveness and articulation scores than 10 male esophagea1 speakers. The mean fundamental frequency measurements between the groups were not significantly different. In this study, no attempt was made to show a relationship between effectiveness ratings and fundamental frequency, but only how female and male esophageal 
speakers differed on various measures. A later publication (Filter and Hyman, 1975) investigated the relationship of these acoustic measures to the effectiveness ratings. Correlational data was not reported according to speaker sex. As with Shipp's study, it appears effectiveness was significantly correlated to mean fundamental frequency when the 20 speakers were considered together. Other parameters in the Filter and Hyman study significantly correlated to effectiveness were intelligibility, articulation, faster rate, and greater mean intensity.

Hoops and Noll (1969), in contrast to Shipp (1967) and Filter and Hyman (1975), did not find fundamental frequency to be a significant factor in judgements of effectiveness. The subject sample, however, was comprised of only male esophageal speakers.

Perhaps the conflicting results of these studies relative to the relationship between fundamental frequency and effectiveness ratings are based on the nature of the subject samples (Hoops and No11, male; Filter and Hyman, male and female; Shipp, unknown). Listeners may apply different standards of social acceptability or effectiveness to a female esophageal voice than to the male, yet this is difficult to interpret from the published data.

Some studies provide some basis for treating female esophageal voices as distinct from the male in perceptual studies. Despite the description of "masculine" given by some to the female esophageal voice (Svane-Knudsen, 1960; Gardner, 1966; Cooper, 1973), Weinberg and Bennett (1975) determined that naive 1isteners reliably and accurately identify the sex of esophageal. speakers from tape-recorded voice samples, and 
that male and female esophageal voices differ significantly in fundamenta1 frequency (Weinberg and Bennett, 1972a).

Stewart (1975) investigated listener reactions to artificia1 larynx, esophageal and Asai speech. Asai speech is the product of a three-stage surgical procedure which allows the laryngectomee to use pulmonary air expired through a dermal tube, activating a pseudoglottis at the base of the tongue. In Stewart's study, each group was represented by one female and three male speakers, and ranked by naive 1isteners. The esophageal, mode was most preferred for male speakers. For females, Asai speech was ranked more acceptable than elther esophageal or artificial larynx speech. Asai speech is breathier and has a higher fundamental frequency than other types of alaryngeal speech, suggesting listener preference for a higher pitch in female alaryngeal speakers. Investigators have treated the relationship between esophageal speakers and listener perceptions in many ways, with conflicting or unreplicated results. Research needs to be completed that not only relates acoustic parameters of esophageal speech to perception of its listeners, but treats male and female esophageal voices as different samples. 
CHAPTER III

METHODS AND PROCEDURES

Methods

\section{General Plan of Study}

Twenty-three esophageal speakers, 11 female and 12 male, were tape-recorded reading a portion of the "Rainbow Passage" (Fairbanks, 1960) and saying a series of monosyllabic words. The second sentence of each speaker's passage was extracted and placed on an audio tape. The samples were rated according to the Barton-Hejna Scale for Esophageal Speech Competency (1960), by three professionals who have experience teaching laryngectomized individuals. From this, a sample of eight male and eight female speakers were matched for speech competency. These 16 esophageal speakers comprised the sample for this investigation.

The second sentence of the reading passage was extracted from each subject sample and placed in two different random orders on an audio tape for presentation to naive 1isteners. To acquaint listeners with the range of voices to be rated, the first presentation consisted of the 16 voices. The voices were then presented in a different random order and the listeners rated each voice on the parameter of relative social acceptability, using a seven-point equal appearing interval scale. The rating form and the audio tape indicated whether the voice to be rated was male or female. : Each monosyllabic word in the series was analyzed 
spectrographically for an estimate of fundamental frequency, and the measured frequencies were averaged.

The 1isteners' ratings and speaker sex were compared to determine if a difference exists between the social acceptability ratings of male and female esophageal voices. The listeners' ratings and the fundamental frequency averages were correlated to determine if any significant relationship exists between fundamental frequency measurements of female esophageal voices and social acceptability ratings by naive 1isteners. The correlation procedure was duplicated for the male esophageal voices aftd ratings of social acceptability. The ratings wete analyzed to determine if male and female listeners rated female esophageal voices in a similar manner.

\section{$\underline{\text { Subjects }}$}

The subject selection for this investigation involved two procedures. Potential volunteer esophageal speakers were contacted through the Portland New Voice Club and M. H. Hollyfield, lay teacher of esophageal speech. Twenty-three speakers who fulfilled the following criteria agreed to be taped:

1. Spoke in General American dialect;

2. Had the ability to read a 51-word passage aloud;

3. Could sustain a vowel for approximately one second.

Part two consisted of playing a speech sample from each volunteer to a panel of three professionals who work with larygectomized individuals. The judges rated each voice on the seven-point Barton-Hejna Scale for Esophageal Speech Competency (Appendix A). From the results of these ratings, eight male and eight female esophageal voices were 
matched for esophageal speech competency and comprised the subjects for this study.

\section{Listeners}

The naive 1isteners were members of undergraduate classes at Portland State University. Students with self-reported normal hearing acuity and no formal contact with esophageal speech were considered qualified listeners. The rating forms of 15 male and 15 female 1isteners were randomly selected for analysis from a total of 50 forms.

\section{Instrumentation}

The speech samples were recorded on Maxel1 35-90 tape with an Artik' Speech and Hearing Recorder, Mode1 414, and accompanying microphone. Samples were recorded at seven and one-half inches per second. Two Sony 105 recorders were used to produce the rating tape, which was dubbed from the master tape. The tape was presented to the 1isteners with a Sony 105 recorder at seven and one-half inches per second.

The four word series from each sample was analyzed spectrographically to determine fundamental frequency with a Kay Sona-graph, Model 6061-B. A Type A display, showing frequency plotted on the ordinate and time on the abscissa, was used (Appendix B).

\section{$\underline{\text { Procedures }}$}

\section{Recording Procedures}

Each sample was collected in a quiet room in the subject's home. The microphone was held six to eight inches in front of the mouth at chin level. Speakers read the first three sentences of the "Rainbow Passage," followed by the words "bid," "bed," "bide," and "bud" 
(Appendix C). These words were chosen because the vowel sounds are represented in the sentence that was presented to the listeners. Specific instructions given verbally to each speaker were:

I am going to record as you read this short passage. After you read it, I want you to say the words printed below in the same way that I demonstrate to you now.

A model was presented demonstrating each monosyllabic word, prolonging the vowel portion approximately one second. The speaker was allowed to practice reading the passage; the objective was for the speaker to be comfortable reading the material. Recordings were made when the speaker indicated he or she was ready to read aloud. This tape is referred to as the "master tape" in this investigation. Selection of subjects from the tape is described in the section "Subjects."

The second sentence read by each speaker who was a subject was extracted and dubbed in two different sections on a second generation tape. The first section consisted of the 16 samples, placed in random order using a random numbers table. This section was presented to listeners to acquaint them with the range of voices involved. The second section consisted of 23 voices placed in a different random order; each sample consisted of the second sentence of the "Rainbow Passage" and the series of four monosyllabic words that were subjected to sonographic analysis. Five of the voices (three male and two female) were randomly selected and presented twice to determine intrajudge reliability. A five-second interval followed each voice to allow the listeners time to rate that voice on a seven-point scale of social acceptability (Appendix D). Each voice was introduced by the carrier phrase "Number one, female... (or whatever the gender)." Each voice was followed by a five-second pause during which the listeners rated that voice. 
$\underline{\text { Rating Procedures }}$

Listeners were informed before the listening task they would hear both female and male esophageal speakers. A seven-point equal appearing interval scale was used to rate the esophageal voices. Each scale indicated the sex of that speaker. No specific definition of social acceptability was given to the listeners, except to explain that an " $\mathrm{X}$ " on the extreme left side of the scale meant "least socially acceptable," and a mark on the extreme right side of the scale meant "most socially acceptable." Actual instructions to the 1isteners are found in Appendix E.

\section{Measurement and Analysis of Data}

Acoustic Measurement

A measure of each speaker's fundamental frequency was determined by calculating the mean fundamental frequency for four monosyllabic words, spoken by each subject after reading the "Rainbow Passage." Resulting values were expressed as a speaker's "fundamental frequency."

\section{$\underline{\text { Statistica1 Analysis }}$}

The Pearson product-moment correlation ( $\underline{r})$ was used to determine intrajudge and interjudge reliability, and to determine if a relationship exists between the fundamental frequency of male and female esophageal voices and ratings of social acceptability. The Wilcoxon matched-pairs signed ranks test was used to determine if a difference exists between social acceptability ratings given to male and female esophageal voices (Siegel, 1956). A t test for dependent means was used to determine whether judge sex was a significant variable in the ratings assigned to esophageal speakers. 


\author{
CHAPTER IV \\ RESULTS AND DISCUSSION
}

$\underline{\text { Results }}$

The purpose of this investigation was to examine social acceptability ratings given by naive listeners to male and female esophageal voices. Additionally, the relationship of fundamental frequency of esophageal voice to listener ratings of voice social acceptability (VSA), relative to esophageal speaker sex, was determined. The relationship between listener sex and perceived esophageal voice social acceptability wảs also examined.

Preliminary to analysis of the data, the Pearson product-moment correlation ( $\underline{r})$ was used to determine intrajudge reliability. Five randomly chosen esophageal voices were rated twice on the seven-point scale for social acceptability; the first rating of each voice was correlated with the second rating of the thirty listeners. As Table I shows, negligible intrajudge reliability was found in the rating comparisons of one esophageal voice, i.e., speaker number four. Low (.20 to .40) to moderate $(.40$ to .70$)$ correlations were found for the remaining voice pairs (Guilford, 1956).

Interjudge reliability on the rating scale data was determined with the Pearson product-moment correlation $(\underline{r})$ for each listener. The rating given by a listener to each voice was compared to the total mean social acceptability rating for that voice. As shown by Table II, 
TABLE I

RATING SCALE INTRAJUDGE RELIABILITY

\begin{tabular}{ccc}
\hline & Sex & $\underline{r}$ \\
\hline 2 & Female & .48 \\
4 & Male & -.04 \\
9 & Male & .32 \\
10 & Female & .65 \\
16 & Male & .54 \\
\hline
\end{tabular}

interjudge reliability ranged from .17 to .90 . It is important to note that, with the exception of the lowest $\underline{r}$, moderate to very, high interjudge rellability was achieved by the 11steners. Tfte metrin was . 115 . Answers to four questions were sought based on the ratings given by naive listeners to male and female esophageal voices. The first question

TABLE II

RATING SCALE INTERJUDGE RELIABILITY

\begin{tabular}{lc}
\hline$\underline{\mathbf{r}}$ Value Ranges & No. of Listeners \\
\hline Less than .20 & 1 \\
$.20-.40$ & 0 \\
$.40-.70$ & 11 \\
$.70-.90$ & 17 \\
$.90-1.00$ & 1 \\
\hline
\end{tabular}


posed was: Is there a difference in the social acceptability ratings given to female esophageal voices compared to male esophageal voices, when the speakers are matched for speaking ability? Appendix F shows the mean social acceptability rating given by male and female listeners to each voice, and the fundamental frequency and Barton-Hejna Scale rating for each voice. The Wilcoxon matched-pairs signed ranks test was used to determine the difference between VSA ratings given to male esophageal voices as compared to female esophageal voices, when the speakers were matched for esophageal speech competency. The resultant T score of 9 was not significant at the .05 level, suggesting that knowing the sex of the esophageal speaker was not a statistically significant variable in the listeners' estimations of voice social acceptability.

The second and third questions asked were: 1) Does a relationship exist between the fundamental frequencies of female esophageal voices and ratings of social acceptability given by naive listeners? and 2) Does a relationship exist between the fundamental frequencies of male esophageal voices and ratings of social acceptability given by naive listeners? Table III shows the mean fundamental frequency for the sample of female

\section{TABLE III}

SAMPLE MEAN FUNDAMENTAL FREQUENCY

\begin{tabular}{cccc}
\hline \hline Speaker Sex & $\overline{\mathrm{X}} \mathrm{F}_{0}$ & Range & $S D$ \\
\hline Female $(\mathrm{n}=8)$ & $98.5 \mathrm{~Hz}$ & $60-123 \mathrm{~Hz}$ & 20.74 \\
Male $(\mathrm{n}=8)$ & $90.3 \mathrm{~Hz}$ & $78-105 \mathrm{~Hz}$ & 10.82 \\
Total $(\mathrm{n}=16)$ & $94.4 \mathrm{~Hz}$ & $60-123 \mathrm{~Hz}$ & 16.52 \\
\hline
\end{tabular}


and male esophageal voices, separate and combined, the range for each sex and associated standard deviations.

The relationship between esophageal voice fundamental frequency and the mean VSA rating was determined by the Pearson product-moment correlation. (r). Table IV shows a moderate correlation between the mean female fundamental frequencies and the VSA ratings given by naive listeners. An $\underline{r}$ of .46 may be interpreted to indicate mean fundamental frequency accounted for approximately 21 percent $\left(\mathrm{r}^{2}=.2116\right)$ of the variance of VSA ratings. By comparison, fundamental frequency was a less significant variable in the VSA ratings of male voices only and when considering the total sample.

The last question posed was: Do male and female naive listeners rate female esophageal voices similarly? Two-tailed $\underline{t}$ tests for dependent means were conducted on the total sample and on female voices alone to determine if listener sex was a variable in the ratings assigned to esophagea1 speakers. Results showed there was no significant difference in the

TABLE IV

MEAN FUNDAMENTAL FREQUENCY AND MEAN VOICE SOCIAL ACCEPTABILITY RATINGS

\begin{tabular}{lcccc}
\hline & & $\bar{x}$ VSA \\
Sample & $\bar{X} F_{0}$ & Rating* & VSA Rating* & $\underline{r}$ \\
\hline Female $(n=8)$ & 98.5 & 4.11 & 1.15 & .99 \\
Male $(n=8)$ & 90.3 & 4.59 & 1.07 & .05 \\
Tota1 $(n=16)$ & 94.4 & 4.35 & .24 \\
\hline \multicolumn{2}{c}{ *Voice Social Acceptability }
\end{tabular}


manner male and female listeners rate female esophageal voices $(\underline{t}=1.3)$ or the total sample of 16 esophageal voices $(\underline{t}=1.5)$.

\section{Discussion}

When listener judgements of a subject's speech or voice are required in an investigation, audience composition and performance are important in consideration of the results. In this study, an individual listener showed only low to moderate agreement with himself in rating two identical esophageal voices. In fact, negligible intrajudge reliability was demonstrated with one voice. The results of this study depend on the perceptions of the listener, inconsistent as they may be, and this must be considered when interpreting the data.

Other findings concerning the listeners suggest there was moderate to high agreement between the listeners for the rating of each particular voice. The naive listeners also had high agreement (.78) with the Barton-Hejna Scale rating given to each esophageal speaker by professionals. This suggests the more competent esophageal speakers were likely to have their voices rated as more socially acceptable by the naive 1isteners. Using the ratings of the professionals as criteria, some degree of validity between the two measures is thus indicated; certain voice characteristics were apparent to both sets of judges. The Barton-Hejna Scale (Appendix A) is a seven-point descriptive scale for the parameters of sentence usage, rhythm and noise of production. On the other hand, the scale used by the naive listeners was an equal appearing interval scale from 1 (least socially acceptable) to 7 (most socially acceptable) with no descriptions of esophageal voice acceptability (Appendix D). 
Listener sex did not significantly effect 1istener ratings scores for female esophageal speakers or in the rating of the total sample of esophageal voices. This finding is in agreement with Stewart (1975) who found that sex of the listener was not a variable in social acceptability ratings for alaryngeal speakers using different modes of speech (esophageal, Asal and artificial larynx users).

The criteria for listeners in the present study was normal hearing and no formal contact with esophageal speakers. Only university students were used (modal age range = 17-22 years); caution should be exercised in projecting results to other segments of the general population.

The speaker's sex was not a statistically significant factor in VSA ratings. The total mean VSA ratings for females was 4.11 (range: $2.54-6.04$ ); for males, 4.59 (range: $3.14-6.14$ ). In other words, given a pair. of male and female esophageal voices matched for speech competency, naive 1isteners made VSA ratings based on factors other than speaker sex. Male esophageal voices did not receive statistically significant higher scores than the female esophageal speakers. It is interesting to note, however, that six of the eight females were given lower VSA ratings than males of equal esophageal speech competence. Filter's (1971) data is not supported. He showed female speakers had significantly higher effectiveness ratings than the male speakers. Filter's listeners were not told the sex of the speaker. The findings of the present study do not imply identical standards for voice social acceptability were considered for each speaker in the sample, as later discussion will reveal. Table $\mathrm{V}$ shows the VSA ratings given to male and 
TABLE V

BARTON-HEJNA RATINGS, MEAN VOICE SOCIAL ACCEPTABILITY

RATINGS, AND FUNDAMENTAL FREQUENCY

FOR MATCHED PAIRS

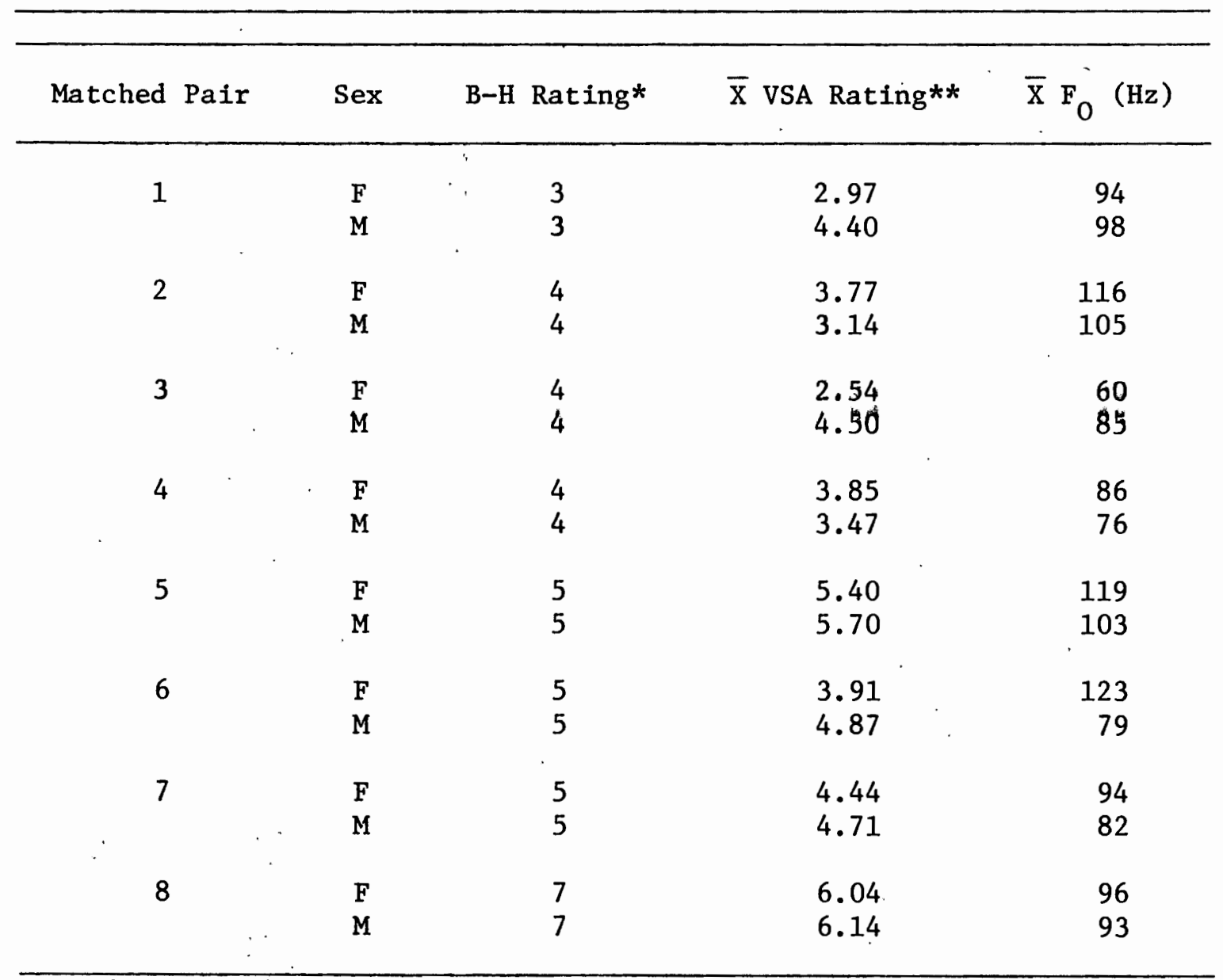

*Barton-Hejna Rating by Experienced Judges

**Mean Voice Social Acceptability Rating 
female members of each matched pair, and the mean fundamental frequency $\left(F_{0}\right)$ for each speaker.

When relating fundamental frequencies of female esophageal voices and VSA ratings, fundamental frequency accounted for 21 percent $\left(r^{2}=\right.$ .2116) of the variance of the ratings. This was not found when correlating the fundamental frequencies of male esophageal speakers and VSA ratings $(\underline{r}=.05)$. When the Pearson product-moment correlation was applied to the total sample of eight male and eight female voices, a low correlation resulted $(\underline{r}=.24)$. Fundamental frequency appears to be a greater factor in the VSA ratings of the female esophageal voices than for the male esophageal voices. Inspection of the individual pairs reveals the female esophageal voice with the lowest fundamental frequency was also given the lowest VSA rating for the entire sample. The VSA rating was between one and two points below all other subjects who were rated at the same level of esophageal speech competency. This subject's fundamental frequency $(60 \mathrm{~Hz})$ was below the range of the men. Because this female's voice was so obviously low compared to the other female voices, a question arises concerning how representative the voice may be of female laryngectomees who use esophageal speech. Table VI shows previous studies that investigated the fundamental frequency of esophageal voice, including the method used to obtain it. The fundamental frequency measurement of $60 \mathrm{~Hz}$ falls well within ranges reported for female samples (Filter, 1971; Weinberg and Bennett, 1972a).

The results from questions two and three are particularly interesting in consideration of earlier studies that correlated acoustic parameters to 1istener ratings of "effectiveness" or "acceptability." Hoops and Noll (1969) related frequency, intensity and rate analyses 


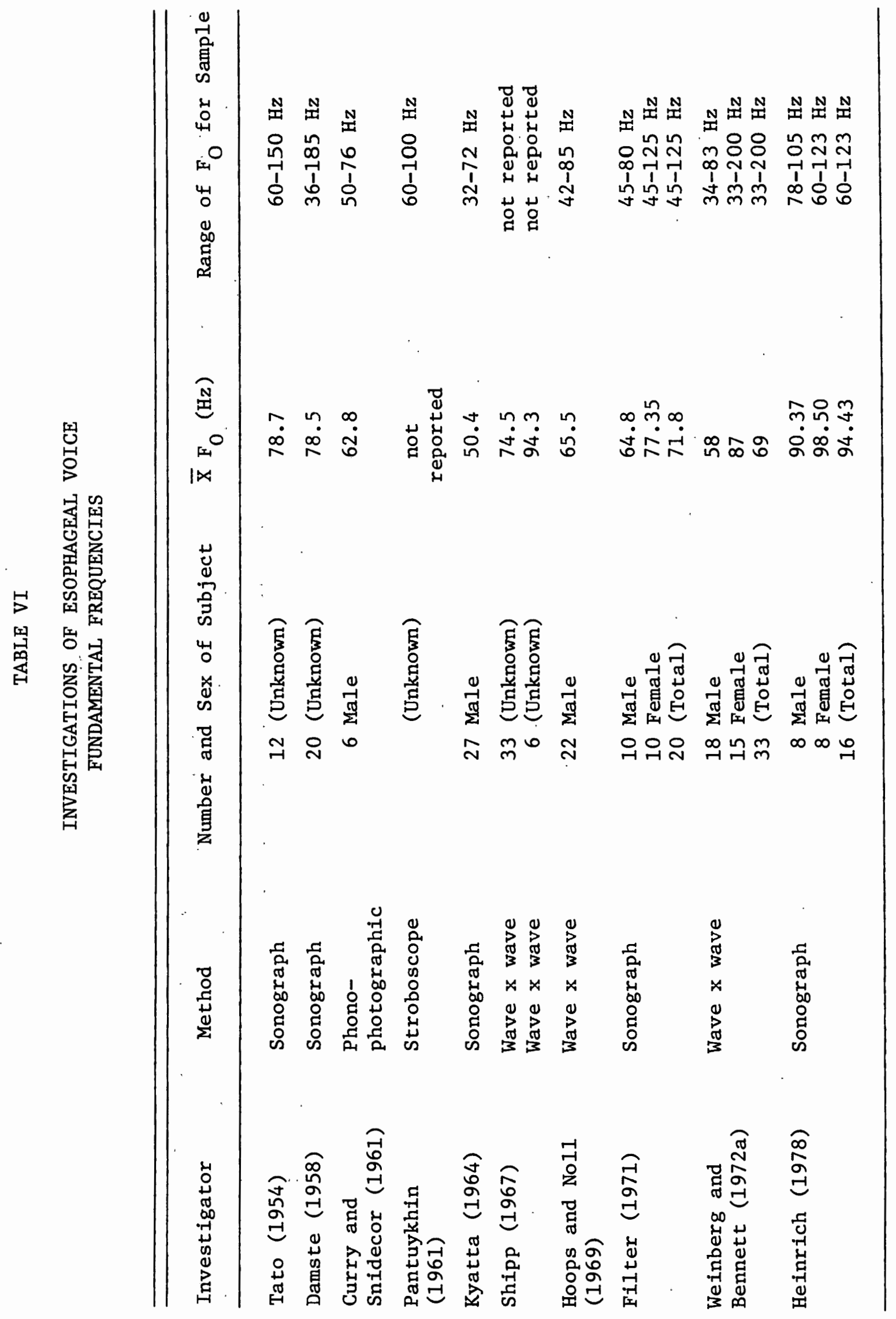


to esophageal speech effectiveness ratings. Only rate was found to be significantly related to speaker effectiveness; however, the sample was composed of 22 male esophageal speakers. It appears, then, the Hoops and Noll data support the findings of the present study that fundamental frequency is not a significant variable in effectiveness ratings of male esophageal speakers.

Shipp (1967) related several acoustic parameters to "acceptability" ratings. Higher fundamental frequencies and faster speaking rates were coincident with above average acceptability ratings. Shipp did not identify the composition of the sample nor report the data with regard to speaker sex. Perhaps the presence of female esophageal voices in the study elevated the significance of the fundamental frequency data, in both the total mean fundamental frequency of the sample, and in the apparent relationship between higher fundamental frequency and above average acceptability ratings. In the present investigation, analysis of the male voices alone indicated fundamental frequency was not a significant factor in acceptability ratings. When the total sample (male and female) was considered, there was a positive correlation between fundamental frequency and acceptability ratings, supporting Shipp. It is important to keep in mind, however, that significance was almost entire1y a function of the female segment of the sample. Based on Shipp's published results, the separate contribution of either male or female speakers is unknown.

The same phenomenon is demonstrated in the study by Filter and Hyman (1975). Ten women and ten men were included in their study relating acoustic and perceptual dimensions of esophageal speech. Results indicated that higher intelligibility, more proficient articulation, 
faster rate, higher fundamental frequency and greater mean relative intensity were positively related to effectiveness. Because results were not reported according to speaker sex, the contribution of the female speakers alone to the significance of the data cannot be determined. A correlation coefficient of $\underline{r}=.54$ indicated approximately 29 percent of the effectivness rating was based on fundamental frequency when the total sample was considered.

In addition to providing a basis for comparison regarding fundamental frequency, data, previous studies provide information of other factors that may effect listener perceptions of esophageal voice or speech acceptability. In this study, fundamental frequency did not appear to be a factor in the male voice ratings; it was not responsible for the majority of the variance in the female voices. Other parameters, perhaps those more amenable to speaker control than fundamental frequency, may have effected listener perceptions in this study. Possibilities include intelligibility, articulation, proportion of periodic phonation, aperiodic phonation and silence, lack of stoma noise, absence of strain in the voice, fluency in going from phrase to phrase, and rate (Berlin, 1965; Shipp, 1967; Hoops and No11, 1969; Filter and Hyman, 1975).

To return to the results of questions one, two and three, there is an implication that while listeners in this study did not rate female esophageal voices as less acceptable than male esophageal voices, fundamental frequency was a factor in the listeners' estimation of female voice social acceptability. It should be noted the range of fundamental frequencies was wider for the females (60-123 Hz) than for the males (78-105 $\mathrm{Hz})$, with the lowest and highest fundamental frequencies being 
produced by female speakers. Interestingly, the ranges reported by other investigators indicate the lowest and highest fundamental frequencies belong to female speakers $(45-125 \mathrm{~Hz}$, Filter, 1971; 33-200 Hz, Weinberg and Bennett, 1972a). Weinberg and Bennett (1972a) noted a statistically significant difference between the mean fundamental frequencies of 18 male and 15 female esophageal speakers. Filter (1971) found no significant difference between the mean fundamental frequencies of 10 female compared to 10 male speakers. The present study supports Filter; a $\underline{t}$ test for independent means resulted in $\underline{t}=1.00$, insignificant at the .05 leve1. Female speakers averaged $98 \mathrm{~Hz}$, compared to $90 \mathrm{~Hz}$ for the males. Generally, the mean fundamental frequencies of speakers in this investigation tended to be higher than those reported in the literature. The fundamental frequencies for the women in this study fall within the range of those reported by Weinberg and Bennett and Filter, though the mean fundamental frequency is higher (98 Hz compared to $77 \mathrm{~Hz}$ and $87 \mathrm{~Hz}$ ). The mean fundamental frequency for males is higher than those reported by studies with male samples: $90.3 \mathrm{~Hz}$ compared to 62.8 $\mathrm{Hz}$ (Curry and Snidecor, 1961), $50.4 \mathrm{~Hz}$ (Kyatta, 1964), $65.5 \mathrm{~Hz}$ (Hoops and Noll, 1969), 64.8 (Filter, 1971), and $58 \mathrm{~Hz}$ (Weinberg and Bennett, 1972a). It compares favorably to Shipp's six highest rated (for acceptability) esophageal speakers $(94.3 \mathrm{~Hz})$. The range for the men in this study falls within ranges found by Damste (1958) and Tato (1964). One might assume these studies used only male subjects because of the preponderance of male laryngectomees compared to females at those early dates (10 males per female in 1965), and the tendency of early investigators to use only male subjects. The comparisons between those studies and the present one, though, must be guarded. 
Shipp (1967) considered the methods used to obtain fundamental frequency as a possible explanation for the wide variance in fundamental frequency among speakers across studies. Weinberg and Bennett (1972b) conducted research that showed a difference existed when a voice was analyzed with wave-by-wave analysis as opposed to the averaging method utilized by Curry and Snidecor (1961); however, the difference was too small to account for the widely discrepant findings in the literature. Weinberg and Bennett suggested actual speaker differences are responsible for the wide range of fundamental frequencies among esophageal speakers. The level of speaker competence probably varies across studies.

Frequency differences have been attributed to selective control by the speaker over whatever muscle group is the principle participator in forming the neoglottis. A laryngectomee who is capable of highly selective contractions of this muscle group may be able to effect the necessary muscle tefistion for a higher volce frequency (Shtpp, 1967). Kyatta (1964) stated the fundamental is definitely related to the shape and 1ocation of the pseudoglottis, though it is greatly influenced by such factors as mucus and variations in esophageal pressure.

Despite the possibility of actual speaker variation, the manner in which fundamental frequency is obtained could affect frequency measurements. In this study, the fundamental frequency for a speaker was determined by sonographic analyses of four prolonged vowel productions; the mean of these was reported. Isolated syllable productions in esophageal. speakers may be at a different fundamental frequency than in "running" speech. Listeners in this study were exposed to both "running" speech and the single syllable utterances. However, extraction 
of words from "running speech" and subsequent sonographic analysis may have represented a truer measure of esophageal voice fundamental frequency. Other investigators have analyzed nonsense syllables sonographically (Filter and Hyman, 1975) and complete sentences or an entire passage using wave-by-wave analysis (Shipp, 1967; Hoops and No11, 1969; Weinberg and Bennett, 1972a) or phonophotographic techniques (Curry and Snidecor, 1961). 
CHAPTER V

SUMMARY AND IMPLICATIONS

Summary

Removal of the larynx necessitates an altered means of speaking. Esophageal voice is the traditional and generally recommended substitute volce. Because the pitch of the female esophageal voice may be strikingly lower than that for normally speaking women, fundamental frequency may be a variable influencing whether female esophageal voice is considered socially acceptable. More importantly, listeners may apply different standards to male and female esophageal voices, thus necessitating an approach in research that treats them as separate samples.

This study proposed to determine if male and female esophageal voices were rated in the same manner by naive listeners. Answers to the following questions were sought:

1. Is there a difference in the social acceptability ratings given to female esophageal voices compared to male esophageal voices, when the speakers are matched for speaking ability?

2. Does a relationship exist between the fundamental frequencies of female esophageal voices and ratings of social acceptability given by naive listeners?

3. Does a relationship exist between the fundamental frequencies of male esophageal voices and ratings of social acceptability given by naive listeners?

4. Do male and female naive listeners rate female esophageal voices simflarly? 
The subjects for this study were eight female and eight male esophageal speakers, matched for speech competency by the Barton-Hejna Scale for Esophageal Speech Competency.

The subjects were tape recorded reading the first paragraph of "Rainbow Passage" and saying a sertes of four CVC syllables with the vowel portions, prolonged. The second sentence, of the passage and the four syllables were extracted and placed on a second generation tape. Listeners then rated each esophageal voice sample for voice social acceptability (VSA). Additionally, the vowel portions of the four monosyllabic words were subjected to sonographic analysis; these were averaged and the average considered to be the "fundamental frequency."

Analysis of the ratings given to male and female speakers indicated that knowing the speaker's sex was not related to social acceptability of esophageal voice. The total mean VSA rating for the male voices was not significantiy different from the total mean VSA rating given to the female voices. These findings do not indicate that ideritical standards of social acceptability are applied to each voice.

Analysis of fundamental frequencies and VSA ratings for female voices shows. a moderate correlation. The fundamental frequency, then, may be considered a factor related to the VSA rating given to a female esophageal voice. A negligible relationship was found when correlating the fundamental frequencies of male esophageal voices and VSA ratings. The necessity of treating male and female esophageal voices as separate samples in perceptual research is supported.

The findings indicate the sex of the listeners did not influence the rating scores assigned to the voices. Male and female listeners 
rated the esophageal voices in a similar manner.

\section{Implications}

\section{Clinical}

The findings of this study may have important implications in counseling the female laryngectomee who dislikes using esophageal voice because of the possible effect of its pitch on listeners. This study showed that 1 isteners do base some perception of social acceptability of the female esophageal voice on its fundamental frequency. However, the majority of the variance (79\%) in the ratings was not based on fundamental frequency. Other parameters of esophageal voice, perhaps those more amenable to speaker control than fundamental frequency, may be more responsible for 1 isteners' perceptual judgements. For both male and female speakers, improved rate, intelligibility, articulation, absence of strain in the voice, decreased stoma noise, and fluency between words and phrases seem to be important clinical goals. Esophageal speakers should be encouraged to continue with clinical intervention for as long as is necessary to produce the most effective speech.

Fundamental frequency should not be completely dismissed, however. Shipp's (1967) hypothesis of selective muscle control by speakers with higher fundamental frequencies may provide a basis for clinical techniques. According to Van den Berg and Moolenaar-Bij1 (1959) and Curry and Snidecor (1961), it is possible to increase frequency variability. Techniques to increase frequency variability may perhaps be applied to increase the overall frequency level. 
$\underline{\text { Research }}$

This study should be replicated using a larger sample of both female and male voices, with comparable ratings in esophageal speech competency. Controlling for factors that may effect listener ratings (rate, intelligibility, articulation, strain, stoma noise, and fluency between phrases) would provide a clearer picture of the contribution of fundamental frequency to voice effectiveness. It would be interesting to compare ratings given to a sample of excellent female esophageal speakers, to determine if voices with a higher fundamental frequency are rated as more effective.

An important implication of this study is the necessity of considering female and male esophageal voices as separate samples, particularly in studies requiring listener's perceptual judgements. It would be of interest to reanalyze findings in previous studies according to speaker sex; pethaps the reported findings would be altered.

It is recommended that future studies of esophageal volce use an alternative means of fundamental frequency analysis. Extraneous noise in the poorer speakers' productions often made analysis of the sonograms difficult. The spectrograph, however, may be useful with excellent esophageal speakers, whose stoma noise and speech air intake noise is minimal. 


\section{SELECTED BIBLIOGRAPHY}

Barton, J. and R. F. Hejna, A Study of Factors Relating to Success or Non-success in the Acquisition of Esophageal Speech. Unpublished paper, Northwestern University Library (1960).

Bennett, S. and B. Weinberg, Acceptability Ratings of Normal, Esophageal and Artificial Larynx Speech. J. Speech Hearing Res., 16, 608-615 (1973).

Berlin, C. I., Clinical Measurement of Esophageal Speech: III. Performance of Non-Biased Groups. J. Speech Hearing Dis., 30, 174-182 (1965).

Berry, R. A. and R. E. Knight, Auditory Versus Audiovisual Intelligibility Measurements of Alaryngeal Speech. Percept. Motor Skills, 49(3), 915-918 (1975).

Christensen, J. and B. Weinberg, Vowe1 Duration Characteristics of Esophageal Speech. J.Speech Hearing Res., 19(4), 678-689 (1976).

Cooper, M., Modern Techniques of Vocal Rehabilitation. Springfield: C. C. Thomas, Publisher (1973).

Curry, E. T. and J. C. Snidecor, Physical Measurement and Pitch Perception in Esophageal Speech. Laryngoscope, 71, 415-424 (1961).

Curry, E. T., J. Snidecor and N. Isshiki, Fundamental Frequency Characteristics of Japanese Asai Speakers. Laryngoscope, 83, 17591763 (1973).

Damste, P. H., Oesophageal Speech After Laryngectomy. Netherlands: Groningen, Publisher (1958). Cited in Kyatta (1964).

DiCarlo, L. M., W. Amster and G. Herer, Speech After Laryngectomy. Syracuse: Syracuse, Publisher (1955).

Diedrich, Wm. and K. A. Youngstrom, Alaryngeal Speech. Springfield, Illinois: C. C. Thomas, Publisher (1966).

Fairbanks, G., Voice and Articulation Drillbook. New York: Harper and Row, publishers (1960).

Filter, M., A Comparison of Male and Female Esophageal Speech. Jour. of Comm. Path., 4, 9-11 (1971). 
Filter, M. and M. Hyman, The Relationship of Acoustic Parameters and Perceptual Ratings of Esophageal. Speech. Percep. Motor Ski11s, $49(1), 63-68$ (1975).

Gardner, W. H., Adjustment Problems of Laryngectomized Women. Arch. Otolaryng., 83, 31-42 (1966).

Gilchrist, A. G., Rehabilitation After Laryngectomy. Acta Otolaryng., $75(66), 511-518$ (1973).

Gilmore, S., Social and Vocational Acceptability of Esophageal Speakers Compared to Normal Speakers. J. Speech Hearing Res., 17(4), 599607 (1974).

Guilford, J. P., Fundamental Statistics in Psychology and Education. $\chi$ Third Edition, New York: McGraw-Hill (1956).

Hoops, H. R. and T. Guzek, The Relationship of Rate and Phrasing to Esophagea1 Speech Profictency. Arch. Otol., 100(3), 190-193 (1974).

Hoops, H. R. and J. D. Noll, Relationship of Selected Acoustic Variables to Judgements of Esophageal Speech. J. Comm. Dis., 2, 1-19 (1969).

Horii, Y. and B. Weinberg, Intelligibility Characteristics of Superior Esophageal Speakers'Presented Under Various Levels of Masking Noise. J. Speech Hearing Res., 18(3), 413-419 (1975).

Hunt, R. B., Rehabilitation of the Laryngectomee. Laryngoscope, 74, 382-394 (1964).

Hyman, M., An. Experimental Study of the Artificial Larynx and Esophageal Speech. J. Speech Hearing Dis., 20(3), 291-299 (1955).

King, P. S., E. Lowlks and G. A. Peirson, Rehabilitation and Adaptation of Laryngectomy Patients. Amer. J. Phys. Med., 97, 192-203 (1968).

Klinger, H., Acceptance Among Esophagea1 Speakers. J. Comm. Dis., 4, 273-277: (1971).

Knox, A. W., Physiology of Esophageal Speech--How Does It Work? Lecture given at the Eleventh Annual Institute in Laryngectomee Rehabilitation, Eastern Washington State University, Cheney, Washington (1978).

Kyatta, J., Spectrographic Studies of Sound Quality of Esophagea1 Speech. Acta Otolaryng., Supp1. 188 (1964).

Lavorato, A., An Investigation of the Airflow Characteristics of Pulmonary Air Expulsion During Esophageal Speech. Unpublished Master's Thesis, Portland State University, Portland, Oregon (1970). 
Levin, N., Speech Rehabilitation After Total Removal of the Larynx. J. Amer. Med. Assoc., 149, 1281-1286 (1952).

Martin, D. E., H. R. Hoops and J. C. Shanks, The Relationship Between Esophageal Speech Proficiency and Selected Measures of Auditory Function. J. Speech Hearing Res., 17(1), 80-85 (1974).

McCroskey, R. and M. Mulligan, The Relative Intelligibility of Esophageal Speech and Artificial Larynx Speech. J. Speech Hearing Dis., $28,37-41$ (1963).

Murray, T. and W. S. Brown, Jr., Intraoral Air Pressure Variability in Esophageal Speakers.. Folia Phoniatr., 27, 237-249 (1975).

Nichols, A. C., Loudness and Quality in Esophageal Speech and the Artificial Larynx. In Speech Rehabilitation of the Laryngectomized, J. C. Snidecor, Ed. Springfield, Illinois: C. C. Thomas, publisher (1962).

Nichols, A. C., Confusions in Recognizing Phonethes Spoketh by Esophageal Speakers. J. Comm. Dis., 9(1), 27-41 (1976) .

Pantuykhin, V. P., Stroboscopy in Patients Following Laryngectomy. Westn. ORL, 23, 69-73 (1961). Cited in Kyatta (1964).

Pressman, J., The Surgery of the Larynx with Especial Reference to Subtotal Laryngectomy. In Speech Rehabilitation of the Laryngectomized, J. C. Snidecor, Editor. Springfield, Illinois: C. C. Thomas (1962).

Putney', F. J., Rehabilitation of Post-Laryngectomized Patients. Ann. Otol., 67, 544-549 (1958).

Robe, E., Surgery and Speech, The Pseudoglottis, and Respiration in Total Laryngectomy. In Speech Rehabilitation of the Laryngectomized, J. C. Snidecor, Ed. Springfield, Illinois: C. C. Thomas (1962).

Salmon, S., Use of Imagery in Teaching Esophageal Speech. Calif. Jour. of Comm. Dis., 2, 17-24 (1971).

Shames, G. H., J. Font and J. Matthews, Factors Related to Speech Proficiency of the Laryngectomized. J. Speech Hearing Dis., 28, 273-287 (1963).

Shanks, J. C., Advantages in the Use of Esophageal Speech by a Laryngectomee. Laryngoscope, 77, 239-243 (1967).

Shipp, T., Frequency, Duration, and Perceptual Measures in Relation to Judgments of Alaryngeal Speech Acceptability. J. Speech Hearing Res., 10, 417-427 (1967). 
Siegel, s., Nonparametric Statistics for the Behavioral Sciences. New $X$ York: McGraw-Hill, Publisher (1956).

Snidecor, J. C., Pitch and Duration Characteristics of Superior Female Speakers. J. Speech Hearing Dis., 16, 44-52 (1951).

Snidecor, J. C., Speech Rehabilitation of the Laryngectomized. C. C. Thomas: Springfield (1962).

Snidecor, J. C., Speech Without a Larynx. In Handbook of Speech Pathology and Audiology, L. E. Travis, Ed. New York: AppletonCentury-Croft, Publishers (1971).

Snidecor, J. C. and E. T. Curry, Temporal and Pitch Aspects of Superior Esophageal Speech. Ann. Oto1., 68, 623-636 (1959).

Snidecor, J. C. and E. T. Curry, How Effectively Can the Laryngectomee Speak? taryngoscoje, $70(1), 62-67$ (1969).

Snidecor, J. C. and N. Isshiki, Vocal and Air Use Characteristics of a Superior Male Esophageal Speaker. Folia Phoniatr., 17, 217-232 (1965a).

Snidecor, J. C. and N. Isshiki, Air Volume and Flow Relationships of Six Male Esophageal Speakers. J. Speech Hearing Dis., 30, 205-216 (1965b).

Stewart, K. D., The Relative Social Acceptability of Three Types of Alaryngea1 Speech. Unpublished Master's Thesis, Portland State University, Portland, Oregon (1975).

Svane-Knudsen, V., The Substituted Voice of the Laryngectomized Patient. Acta Otolaryng., 52, 85-93 (1960).

Tato, I., N. Mariani, E. DePiccoli and P. Mirasov, Study of the Soma Spectrographic Characteristics of the Voice in Laryngectomized Patients. Acta Otolaryng., 44, 431-438 (1954).

Tikofsky, R., The Comparison of Intelligibility of Esophageal and Normal Speakers. Folia Phoniatr., 17, 19-32 (1965).

Van den Berg, J. and A. Moolenaar-Bijl, Crico-pharyngeal Sphincter, Pitch, Intensity and Fluency in Esophageal Speech. Prac. OtoRhino-Laryngol., 21.(4), (1959). Cited by Kyatta (1964).

Weinberg, B. and S. Bennett, Selected Acoustic Characteristics of Esophageal Speech Produced by Female Laryngectomees. J. Speech Hearing Res., 15, 211-216 (1972a).

Weinberg, B. and S. Bennett, A Comparison of the Fundamental Frequency Characteristics of Esophageal Speech Measured on a Wave-By-Wave and Averaging Basis. J. Speech Hearing Res., 15, 351-355 (1972b). 
Weinberg, B. and S. Bennett, Study of Talker Sex Recognition of Esophageal Voices. J. Speech Hearing Res., 14, 391-395 (1975). 


\author{
APPENDIX A \\ BARTON-HEJNA RATING SCALE FOR ESOPHAGEAL SPEECH
}

1. No sounds produced; cannot voluntarily produce belch.

2. Partial control of belch; with occasional vowel sound, but inabi1ity to combine vowel and consonants to form words.

3. Some simple words produced; of one or two syllables. No phrases.

4. Combines two or three words in phrases; but production is not smooth or well coordinated. Stops for obvious intake of air between phrases.

5. Some sententice usage; can carry through short sentences on one intake of air, or produces phrases with only slight pauses between phrases.

6. Quite good use of sentences; with only slight noise of production.

7. Very good speech. Even rhythm; almost imperceptible intake of air. Difficult to differentiate from a normal but hoarse voice. 
TYPE "A" SONOGRAM DTSPLAY
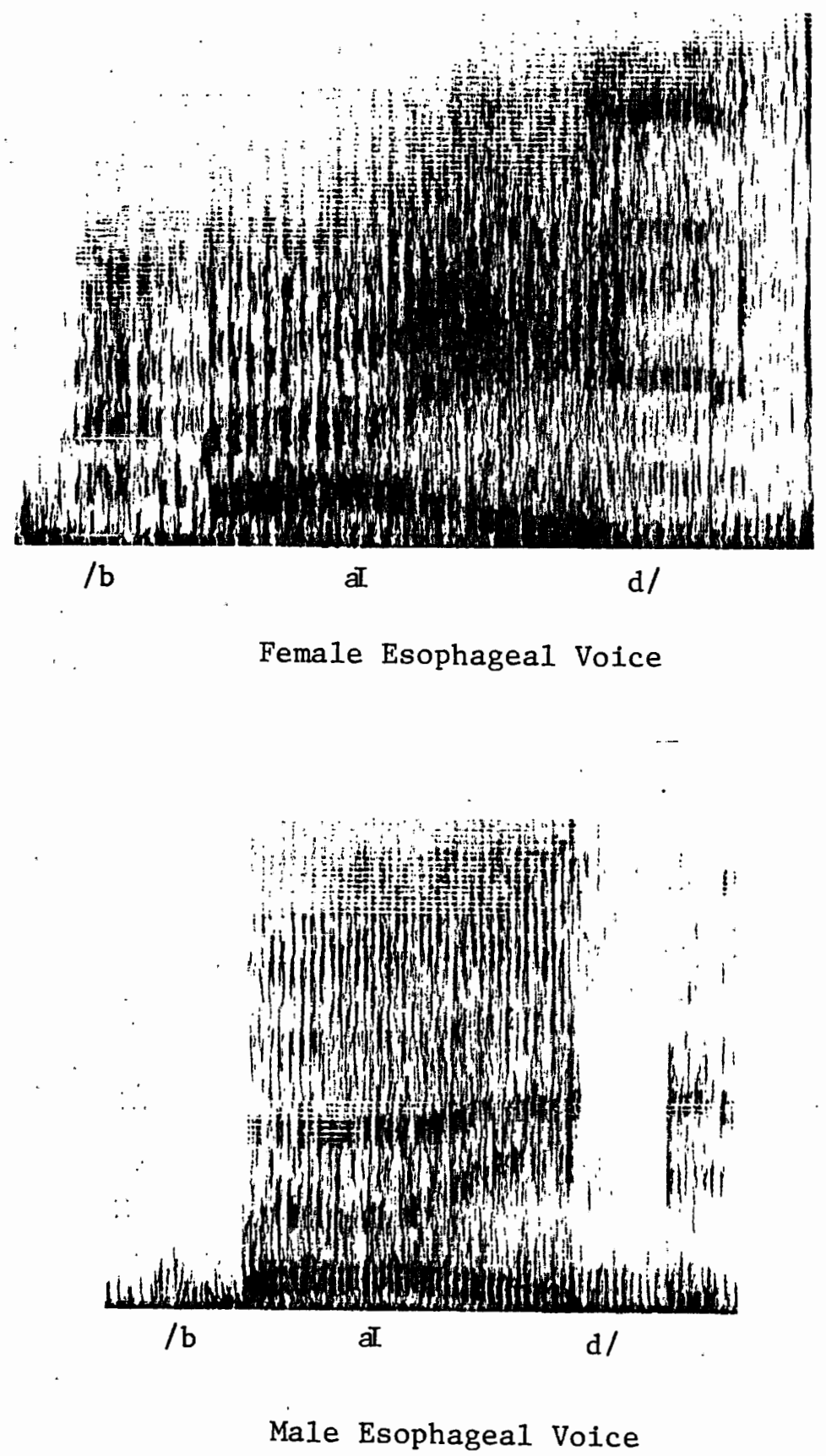


\section{APPENDIX C}

\section{PORTION OF THE RAINBOW PASSAGE}

When the sunlight strikes the raindrops in the air, they act like a prism and form a rainbow. The rainbow is a division of white light into many beautiful colors. These take the shape of a long round arch, with its path high above, and its two ends apparently beyond the horizon.

BID

BED

BIDE

BUD 
APPENDIX D

RELATIVE SOCIAL ACCEPTABILITY OF ESOPHAGEAL SPEECH

Listener's age:
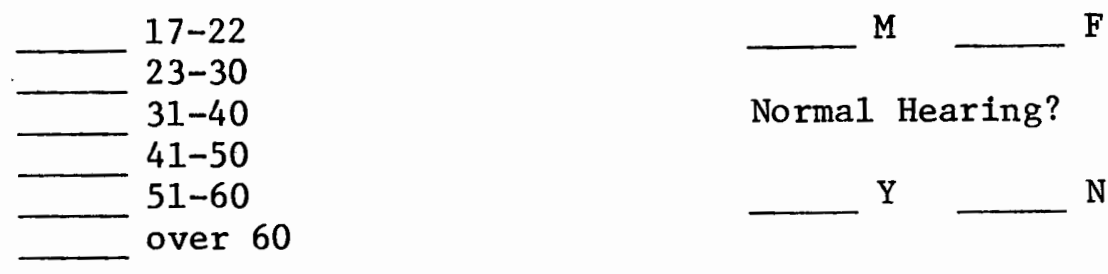

What is the extent of your exposure to alaryngeal speakers? None Very Little (Informally, once or twice)

Section one: Listen only, no rating.

Section two:

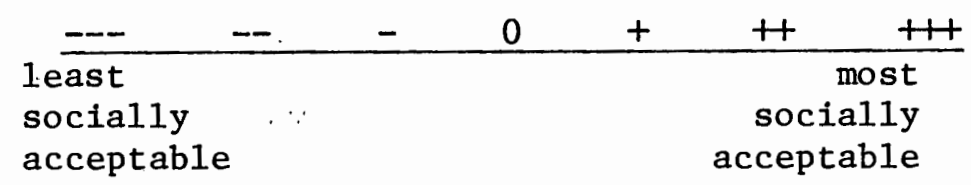

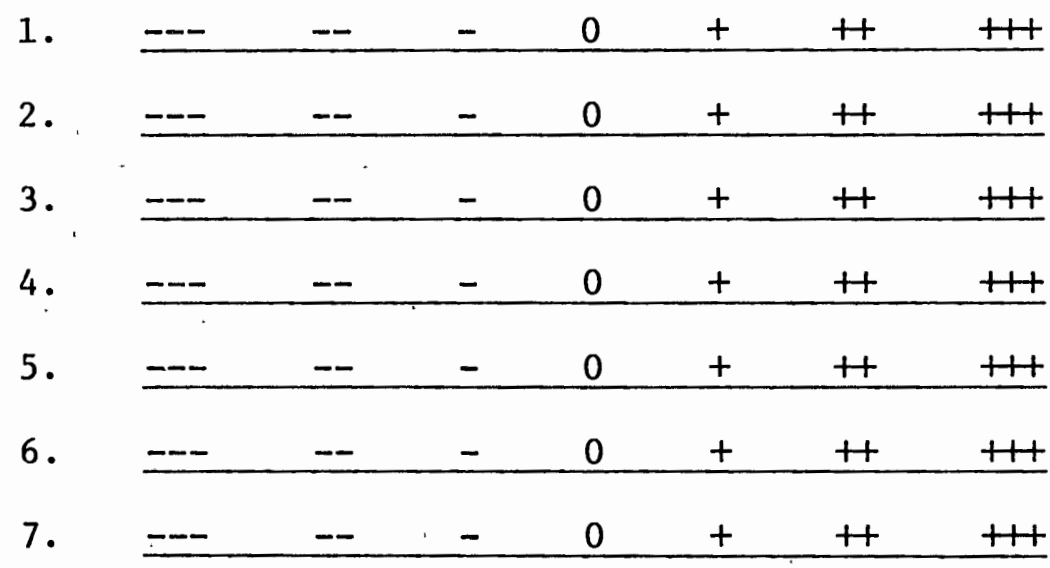


APPENDIX E

\section{INSTRUCTIONS TO LISTENERS}

You are about to listen to a tape of speakers who have had their larynxes (voiceboxes) removed. They have relearned to speak in a different way, called esophageal speech. Each speaker will be reading one sentence: "The rainbow is a division of white light into many beautiful colors." This will be followed by the words "bid, bed, bide, bud," with the vowel sounds elongated. Only listen during the first presentation to acquaint yourselves with the range of voices involved. For the second presentation, you will rate the voices for social acceptability. The sex of each speaker is noted on each scale. The left hand side of each scale indicates the least socially acceptable, the right hand side indicates the most socially acceptable. Keeping the range of voices in mind, rate each where you believe it to belong on the continuum by marking an " $\mathrm{X}$ " on the symbols. Each voice will be introduced by the carrier phrase "Number one, female... (or whatever the case)." Each voice will be followed by a five second pause during which you will rate that voice. Are there any questions? Be sure to answer the questions at the top of the form. 


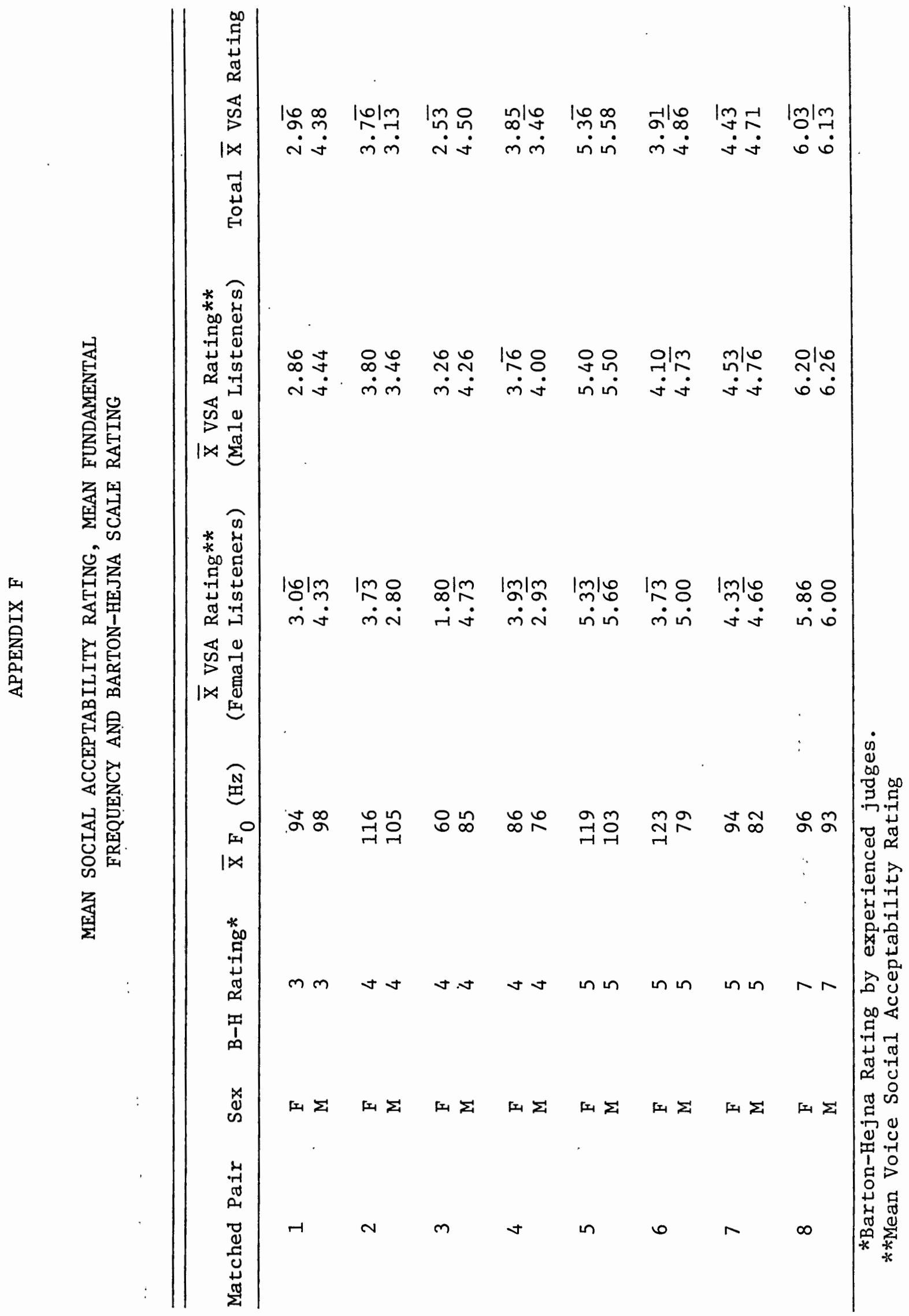

